infected with HIV or not. Mortality in these outbreaks has been high, and measures to control tuberculosis are therefore being urgently reviewed in the United States. In the Medical Research Council's surveys of notifications of tuberculosis in England and Wales in 1978-9, 1983, and 1988, 95\% or more of initial isolates of $M$ tuberculosis from respiratory specimens from previously untreated patients were fully sensitive to isoniazid, rifampicin, ethambutol, and streptomycin..$^{112122}$ In the 1988 survey resistance to isoniazid was present in only $1 \%$ of specimens from white patients and in 3\% of those from people of Indian subcontinent origin. In only seven patients $(0.8 \%)$ were strains isolated that were resistant to more than one drug; none was resistant to both isoniazid and rifampicin.

The Mycobacterium Reference Unit of the Public Health Laboratory Service reports a small increase in strains resistant to isoniazid in 1991 (unpublished data), but it is too early to assess the importance of this increase. Although a small number of multiresistant strains have been received by the Mycobacterium Reference Unit from various parts of England and Wales, none has been formally reported in association with HIV infection and no outbreaks are known to have occurred. The experience in the United States, and particularly in New York, makes it essential that vigilance for such cases should be maintained and procedures to control infection reviewed. ${ }^{23}$

Though undernotification of tuberculosis in Britain is well recognised, its extent is unknown. Some $27 \%$ of cases were not notified in a recently published study of over 600 cases in east London; in another inner London district $18 \%$ of 438 cases were not notified. ${ }^{24}{ }^{25}$ Little information is available for other parts of England and Wales. In a Scottish study in $1981-4,40 \%$ of 69 histopathologically confirmed cases of tuberculosis were not notified. ${ }^{26}$ The scope for improvement is therefore considerable. The appointment of a new cadre of consultants responsible for communicable disease control may have increased the proportion of cases notified, but there is no way of knowing this.

A further national survey of notifications of tuberculosis is being conducted in England and Wales this year, ${ }^{27}$ with a parallel study planned for Scotland. This will estimate notification rates in different ethnic groups, assess trends over time, and obtain information about clinical features and treatment. A new feature of this survey is that the prevalence of HIV infection will be estimated in all adults aged 16 to 54 notified with tuberculosis during the year, using the well established unlinked anonymous HIV testing methodology. ${ }^{28}$ Information from this year's survey will help clinicians in their approach to investigating and managing suspected tuberculosis. It will also assist in the planning of future measures to control tuberculosis, including BCG immunisation policy (see editorial below).$^{29}$
Different factors seem to be responsible for the recent changes in notifications of tuberculosis worldwide. These changes may have relevance to Britain, and we must maintain vigilance. Notification of all cases of tuberculosis remains essential not only for local control but also to strengthen our understanding of the occurrence of the disease through epidemiological surveillance.

Consultant Epidemiologist

JOHN M WATSON

PHLS Communicable Disease Surveillance Centre,

London NW9 5EQ

1 De Cock K, Soro B, Coulibaly IM, Lucas SB. Tuberculosis and HIV infection in sub-Saharan Africa. FAMA 1992;268:1581-7.

2 Rieder HL, Cauthen GM, Kelly GD, Bloch AB, Snider DE. Tuberculosis in the United States. IAMA 1989;262:385-9.

Snider DE, Roper WI. The new tuberculosis. N Engl F Med 1992;326:703-5.

4 Gordin F. Tuberculosis control: back to the future? fAMA 1992;267:2649-50.

5 Rieder HL. Misbehaviour of a dying epidemic: a call for less speculation and better surveillance. Tubercle and Lung Disease 1992;73:181-3.

6 Centers for Disease Control. Nosocomial transmission of multi-drug-resistant tuberculosis among HIV-infected persons-Florida and New York, 1988-1991. MMWR 1991;40:585-91. (Abstract.)

7 Centers for Disease Control. Nosocomial transmission of multi-drug resistant tuberculosis to health-care workers and HIV infected patients in an urban hospital-Florida. MMWR 1990;39:718-22.

8 Di Perri G, Cruciani M, Danzi MC, Luzzati R, Chcchi GD, Malena M, et al. Nosocomial epidemic of active tuberculosis among HIV-infected patients. Lancet 1989;334:1502-4.

9 Office of Population Censuses and Surveys. Infectious diseases, December quarter 1991. London Government Statistical Service, 1993. (OPCS monitor series MB2 93/1.)

10 Office of Population Censuses and Surveys. Registrar general's weekly return for England and Wales. Week ended 25 December 1992. London: Government Statistical Service, 1992. (OPCS monito series WR92/52.)

11 Medical Research Council Cardiothoracic Epidemiology Group. National survey of notifications of tuberculosis in England and Wales in 1988. Thorax 1992;47:770-5.

12 British Thoracic and Tuberculosis Association. A tuberculosis survey in England and Wales 1971; the influence of immigration and country of birth upon notifications. Tubercle 1973;54:249-60.

13 Department of the Environment. Homelessness statistics. London: HMSO, 1987.

14 Pitchenik AE, Cole C, Russell BW, Fischl MA, Spira TJ, Snider DE. Tuberculosis, atypical mycobacteriosis, and the acquired immunodeficiency syndrome among Haitian and non-Haitian patients in south Florida. Ann Intern Med 1984;101:641-5.

15 Centers for Disease Control. Revision of the CDC surveillance case definition for acquired immunodeficiency syndrome. MMWR 1987;36:1S-15S.

16 Centers for Disease Control. 1993 Revised classification system for HIV infection and expanded surveillance case definition for AIDS among adolescents and adults. MMWR 1992;41(RR17): $1-19$.

17 Selwyn PA, Hartel D, Lewis VA, Schoenbaum EE, Vermund SH, Klein RS, et al. A prospective study of the risk of tuberculosis among intravenous drug users with human immunodeficiency virus infection. NEngl I Med 1989:320:545-50.

18 Watson JM, Gill ON. HIV infection and tuberculosis. BMF 1990;300:63-5.

19 Helbert M, Robinson D, Buchanan D, Hellyer T, McCarthy M, Brown I, et al. Mycobacterial infection in patients infected with the human immunodeficiency virus. Thorax 1990;45:907-8.

20 Watson JM, Meredith SK, Whitmore-Overton E, Bannister B, Darbyshire JH. Tuberculosis and HIV: estimates of the overlap in England and Wales. Thorax (in press).

21 Medical Research Council Tuberculosis and Chest Diseases Unit. National survey of tuberculosis notifications in England and Wales 1978-9. BMF 1980;281:895-8.

22 Medical Research Council Tuberculosis and Chest Diseases Unit. National survey of notification of tuberculosis in England and Wales in 1983. BMF 1985;291:658-61.

23 Pozniak A, Watson JM. Nosocomial transmission of tuberculosis in AIDS care centres. Communicable Disease Report 1992;2:R40-2.

24 Sheldon CD, King K, Cock H, Wilkinson P, Barnes NC. Notification of tuberculosis: how man cases are never reported? Thorax 1992;47:1015-8

25 Roderick PJ, Connelly JB. The problems of monitoring tuberculosis in an inner-city health district: integrated information is required. Public Health 1992;106:193-201.

26 Bradley BL, Kerr KM, Leitch AG, Lamb D. Notification of tuberculosis: can the pathologist help? $B M \mathcal{F}$ 1988;297:595.

27 National survey of tuberculosis notifications. Communicable Disease Report 1993;3:1.

28 Gill ON, Adler MW, Day NE. Monitoring the prevalence of HIV: foundations for a programme of unlinked anonymous testing in England and Wales. BMF 1989;299:1295-8.

29 Citron KM. BCG vaccination against tuberculosis: British and global perspectus. BMF 1993;306: $222-3$

\title{
BCG vaccination against tuberculosis: international perspectives
}

\section{Vaccinate the newborn in developing countries and those at risk in developed countries}

The risk of tuberculosis in young white adults in England and Wales has fallen greatly over the past 20 years, and as a result the discontinuation of BCG vaccination at the age of 13 has been proposed.' A national survey of notifications of tuberculosis in England and Wales is to be conducted this year before any decisions are made, but in the meantime controversy continues over the shape of the BCG programme in the United Kingdom. At least in the United Kingdom the evidence of the vaccine's efficacy is strong. In developing countries, where evidence on efficacy is less clear cut, a different controversy exists over whether BCG vaccination programmes are useful at all.

In England and Wales in 1969, 460 vaccinations were needed to prevent one notification of tuberculosis whereas in 1989,3600 were needed. A decision to discontinue vaccination for 13 year olds will depend on anticipating a contin- 
uing decline in notification rates in young adults. Total notification rates in England and Wales declined until 1987, but since then there has been a small increase both in the United Kingdom and in several other European countries. The reasons for the increase are uncertain but may be related to immigration, unemployment, homelessness, and HIV infection. All these factors will be investigated in the national survey of notifications.

In Britain the evidence that BCG protects against tuberculosis is conclusive. ${ }^{2-4} \mathrm{~A}$ large randomised controlled trial of BCG in 14 year olds started in 1950 showed protective efficacy averaging $77 \%$ over 20 years of follow up. ${ }^{2}$ Since 1953 schoolchildren have routinely received BCG at the age of about 13, and retrospective cohort analyses in 1973, 1978, and 1983 showed an efficacy of about $75 \%$ throughout the period. ${ }^{3}$ Vaccination of Asian children born in England, evaluated in two case-control studies, also showed substantial protection in this high risk group..$^{5-6}$

The high and consistent efficacy of BCG vaccination in Britain contrasts with the disparate results reported from other parts of the world. Randomised controlled trials in Haiti and two from the United States showed high efficacy, but three other studies in the United States, two in south India, and one in Puerto Rico showed little or no protection. ${ }^{7}$ The explanations for these apparently widely differing findings include differences in the vaccines' potency; vaccination techniques; and the age, genetics, and nutrition of the participants.

In some tropical developing countries infection by environmental non-tuberculous mycobacteria may protect against tuberculosis and may therefore reduce or abolish the demonstrable efficacy of BCG vaccination. Communities may differ in the relative proportion of tuberculous disease due to endogenous reactivation and exogenous reinfection, and BCG may give better protection against reactivation than against reinfection. But no single explanation seems adequate to explain all the differences, and several mechanisms are probably responsible. ${ }^{7-9}$

The widespread use of BCG in developing countries came under challenge after a large, detailed, and prestigious study conducted in Chingleput, south India, produced negative results. ${ }^{10}$ The World Health Organisation reviewed this trial in 1980 and concluded that while the results were valid they might not apply in other countries because of the unprecedented behaviour of tuberculosis in the trial area. Also the trial was not designed to establish the efficacy of BCG vaccination in newborn or older children, ${ }^{911}$ and the WHO recommended that countries with a high prevalence of tuberculosis should continue and expand programmes for BCG vaccination of newborn and young children. It recognised the urgent need to evaluate the programme in developing countries.

\section{Case finding and chemotherapy}

Case finding and chemotherapy are the most effective methods of controlling tuberculosis. In developing countries young children usually acquire tuberculous infection in the home before the disease is diagnosed in the index case, sometimes resulting in disseminated and meningeal disease, which is still often fatal in young children. Only the effective vaccination of infants is likely to reduce this risk. Factors that have been suggested to explain the reduced efficacy of BCG, including infection by environmental mycobacteria and a predominance of disease due to exogenous reinfection, are less likely to apply to young children.

In developing countries randomised controlled trials of the efficacy of BCG are inappropriate because of their high cost and long duration. Case-control, contact, and cohort studies are cheaper, quicker, and more realistic, measuring the efficacy of vaccination given routinely by community health services ( $P$ G Smith, paper presented at 26 th world congress of the International Union Against Tuberculosis, Tokyo, 1986).

Studies using these methods to examine vaccination of the newborn and children up to the age of 6 years in Togo, ${ }^{12}$ South Africa, ${ }^{13}$ Thailand, ${ }^{14}$ Korea, ${ }^{15}$ and Argentina ${ }^{7}$ have shown efficacies of 53-74\%. Studies in Indonesia (J Putrali et al, paper presented at eastern region tuberculosis conference of the International Union Against Tuberculosis, Jakarta, 1983) and Burma ${ }^{16}$ showed low overall protection but good protection against meningeal and disseminated disease. In six studies in which meningitis was separately evaluated the protective efficacy was $52-100 \%{ }^{17}$ (P G Smith, 26th world congress of the International Union Against Tuberculosis). In six other studies that included older children and adults efficacy varied widely, mirroring the disparate results of controlled trials ${ }^{71}$ (P G Smith, 26th world congress of the International Union Against Tuberculosis).

The reasons for this variation need elucidation. International agencies should cooperate with developing countries to help them apply new epidemiological and immunological techniques to investigate the vaccines and the host reaction in both tuberculosis and leprosy; vaccines and their applicability to different populations could then be improved.

In the meantime we can conclude that BCG vaccination of the newborn usually protects against serious forms of tuberculosis, is safe and cheap, and should be used in developing countries where tuberculosis is most prevalent. In Britain and in other developed countries with a low prevalence of tuberculosis BCG should be given to high risk groups, including immigrants and their newborns and contacts of patients with tuberculosis. Vaccination of hospital staff and others at higher risk of being exposed to tuberculosis may also become increasingly important in view of the epidemics of multidrug resistant tubercle bacilli occurring in patients with HIV infection in the United States. ${ }^{19}$

Consulting Physician,

K M CITRON

Royal Brompton National Heart and Lung Hospital, London SW3 6NP

\footnotetext{
1. Springett VH, Sutherland I. BCG vaccination of schoolchildren in England and Wales. Thorax 1990;45:83-8.

2 Hart PD'A, Sutherland I. BCG and vole bacillus vaccines in the prevention of tuberculosis in adolescence and early adult life. $B M \mathcal{F} 1977$;ii:293-5.

3 Sutherland I, Springett VH. Effectiveness of BCG vaccination in England and Wales in 1983. Tubercle 1987;68:81-92.

4 Capewell S, France A, Uzel N, Leitch AC. The current value of tuberculin testing and BCC vaccination in school children. Br $\mathcal{J}$ Dis Chest 1986;80:254-64.

5 Rodrigues LC, Gill DN, Smith PG. BCG vaccination in the first year of life protects children of Indian subcontinent ethnic origin against tuberculosis in England. Epidemiol Community Healt 1991;54:78-80.

6 Packe GE, Innes JA. Protective effect of BCG vaccination in infant Asians: a case control study Arch Dis Child 1988;63:964-6.

7 Fine PEM. BCG vaccination against tuberculosis and leprosy. Br Med Bull 1988;44:691-703.

8 Hart PD'A. Efficacy and applicability of mass BCG vaccination to tuberculosis control. BMF 1967;i:587-92.

9 Ten Dam HG. Research on BCG vaccination. Advances in Tuberculosis Research 1984;21:79-106.

10 Tuberculosis Prevention Trial. Trial of BCG vaccine in south India for tuberculosis prevention: first report. Bull World Health Organ 1979;57:819-27.

11 WHO Study Group. BCG vaccination policies. WHO Tech Rep 1980;No 652

12 Tidjani O, Amedome A, Ten Dam HG. The protective effect of BCG vaccination of the newborn against childhood tuberculosis in an African community. Tubercle 1986;67:269-8

13 Cartwright JD. BCG vaccination of the newborn. $S$ Afr Med f 1978;54:65-7.

14 Padungchan S, Konjanart S, Kasiratta S, Daramas S, Ten Dam HG. The effectiveness of BCC vaccination of the newborm against childhood tuberculosis in Bangkok. Bull WHO 1986;64: 247-85.

15 Jin BW, Hong YP, Kim SJ. A control study to evaluate the BCG vaccination programme in Seoul. Tubercle 1989;70:241-8.

16 Myint TT, Win H, Aye HH, Kwaw-mint TO. Case control study on evaluation of BCG vaccination of newborns in Rangoon, Burma. Ann Trop Paediatr 1987;7:159-66.

17 Milstien JB, Gibson JJ. Quality control of BCG vaccine by WHO: a review of factors that may Milstien JB, Gibson JJ. Quality control of BCG vaccine by WHO: a
influence vaccine effectiveness and safety. Bull WHO 1990;68:93-107.

18 Ponninghaus JM, Fine PEM, Sterie JAC, Wilson RJ, Msosa E, Gruer PJK, et al. Efficacy of BCG vaccine against leprosy and tuberculosis in northern Malawi. Lancet 1992;339:636-9.

19 Greenberg PD, Lax KG, Schechter CP. Tuberculosis in house staff. A decision analysis comparing tuberculin screening strategy with BCG vaccination. Am Rev Respir Dis 1991;143:490-5.
} 